\title{
Teaching physics in a physiologically meaningful manner
}

\author{
Michael Plomer, ${ }^{1,2, *}$ Karsten Jessen, ${ }^{1, \dagger}$ Georgi Rangelov, ${ }^{1}$ and Michael Meyer ${ }^{2}$ \\ ${ }^{1}$ Physikalische Praktika, Ludwig-Maximilians-Universität München, Edmund-Rumpler-Straße 9, 80939 München, Germany \\ ${ }^{2}$ Physiologisches Institut, Ludwig-Maximilians-Universität München, Pettenkoferstraße 12, 80336 München, Germany
}

(Received 23 April 2010; published 29 September 2010)

\begin{abstract}
The learning outcome of a physics laboratory course for medical students was examined in an interdisciplinary field study and discussed for the electrical physiology ("Propagation of Excitation and Nerve Cells"). At the Ludwig-Maximilians-University of Munich (LMU) at a time about 300 medicine students were assessed in two successive years. Students from the control group worked with standard experiments, while students from the treatment group performed newly developed "addressee-specific" experiments, designed to guide students to transfer physics knowledge to physiological problems. The assessment took place within the laboratory course on physiology, after the students had finished their laboratory classes in physics, and consisted of the construction of a concept map with additional multiple choice questions. The results showed that standard physics experiments are not adequate for teaching students to transfer physical principles to physiology. Introducing new addressee-specific experiments enriched the physics laboratory course by improving student attitudes toward physics and demonstrating better ability of students to relate concepts of physics and medicine, and overall to improve their understanding of the physics taught in the course.
\end{abstract}

DOI: 10.1103/PhysRevSTPER.6.020116

PACS number(s): 01.40.Fk, 01.50.Pa, 01.50.Qb

\section{EDUCATIONAL OBJECTIVES FOR A PHYSICS LABORATORY AT MEDICAL SCHOOLS}

A physics laboratory course is part of the premedical or medical curriculum at most universities or medical schools. Advanced students need a working knowledge of physics, e.g., that can be transferred to physiology. Such a knowledge transfer is an essential precondition for answering physiological questions with physical arguments.

Unfortunately physics laboratory courses are usually taught by physicists without a medical background, having more or less precise conceptions of educational objectives for the physics laboratory. A comparison of different studies shows a variety of objectives desired by physicists [1-3], and it comes to no surprise that teachers of medicine emphasize only a few of them [4].

To make matters worse, the educational effectiveness of laboratory instruction often remains a point of contention [5-7]. Mismatches between the teachers' intentions and the students' learning outcome have been identified [8], and in addition, the differences in laboratory settings, which were often poorly reported, make comparisons difficult [9]. However, a thorough development of dedicated laboratory experiments can have a positive impact on selected educational goals [10].

Regarding laboratory experiments for medical students, there are requests by medical teachers for the acquisition of both scientific skills and physiologically relevant physics knowledge instead of pure basic physics $[4,11]$. On the other hand, the general implementations of the corresponding laboratory exercises contain "cookbook recipes," which often provide too little physical understanding [12]. Despite these shortcomings, few attempts have been made to modify

\footnotetext{
*michael.plomer@physik.uni-muenchen.de

${ }^{\dagger}$ karsten.jessen@physik.uni-muenchen.de
}

physics education for medical students. Focusing on the physics lecture the inclusion of medical applications and contextual problems into the lecture meets the students' requests for medical relevance [13]. Similarly, the physics laboratory course can profit from making the medical relevance more apparent [4].

In these studies medical topics or suggestions of physiologists were incorporated into physics courses. At most an improvement in the students' attitude toward physics was observed afterward, though neither the impact on later physiology courses nor the general learning outcome from a medical point of view was evaluated.

The present study presents a new design for experiments, emphasizing the physiological relevance of selected physical topics. The success in transferring physics concepts learned in two newly designed laboratory experiments was analyzed from a physiologist's point of view.

\section{DIFFERENT DESIGNS FOR EXPERIMENTS IN THE PHYSICS LABORATORY}

\section{A. Standard experiments}

Standard physics experiments for medical students are often a reduced variant of those for physicists and can be found at many universities or medical schools. In these, students deal at length and intensively with physical concepts and laws solely within the context of physical problems or applications [Fig. 1(A)].

In contrast, medical teachers want students to relate concepts in physics to physiological questions [Fig. 1(B)]. However, this is not exciplitly brought into standard laboratories, and so the transfer must be done by the students themselves. Because there are generally no apparent parallels between the experimental setup and the medical tasks, the direct transfer is unlikely [Fig. 1(C)].

\section{B. Addressee-specific experiments}

The idea of an addressee-specific physics laboratory course for medical students was systematically realized by 


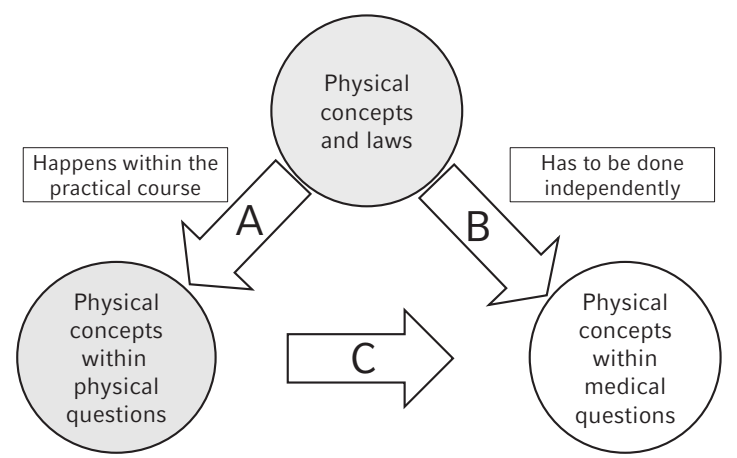

FIG. 1. Standard experiments (gray) within physical and medical domains. For details concerning the arrows A, B, and C see text.

Theyßen et al. for the first time [4]. The experiences of physicists, who taught medical students, and the wishes of medical teachers were taken into consideration while designing experiments that addressed medical examples and applications. Increasing student motivation and more intensive work within the laboratory was reported.

These findings are in accordance with the authors' experiences in the physics laboratory courses at the LMU. As reinforced by the medical teachers' educational requests, the addressee-specific approach gives a methodical and didactic framework for developing new experiments with a high degree of medical relevance. Four criteria are suggested for defining addressee-specific experiments. These criteria describe the settings applied to the treatment group of this study.

\section{Level of difficulty}

Concepts and laws are explained intuitively in the laboratory manual, because the students need to come to the laboratory with an understanding of the phenomena within the experiments [14]. Instead of calculus-based derivations of equations or physical laws, these are motivated by proportionality thoughts, dimensional analysis, analogies, and didactic approaches.

\section{Physiology within the learning material}

Each chapter of the laboratory manual is followed by selected medical or biological examples, which refer directly to the fundamental topics of this chapter. Thus relations to medicine are consistently illustrated during the preparation phase.

\section{The experiment as a model for physiological situations}

Meaningful experimental setups are developed to visualize direct references to medicine. Additionally, the description of the procedure illustrates the medical application of the experiments.

\section{Medical viewpoint during the analysis}

After analysis of the measured data, the results are discussed with regard to their medical relevance. In this context

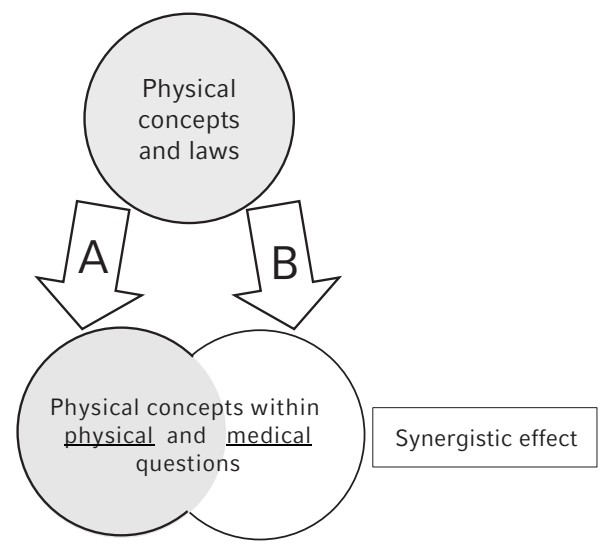

FIG. 2. Addressee-specific experiments (gray) within physical and medical domains. For details concerning the arrows A and B see text.

the values of physical quantities are examined from a physiological point of view.

By changing the content of an experiment from a pure physical question to a both physical and medical one, the students' attitude toward physics improves [4], but additionally they also profit from synergistic effects as learning in a new context. In these experiments the transfer of knowledge from physics to physiology [Fig. 2(B)] is part of the connection of theory and practice [Fig. 2(A)]. As the new experimental setup tries to close the gap between the physics experiment and the medical question, the students no longer have to master the transfer entirely by themselves.

\section{Laboratory alternatives for electricity experiments}

Initially, detailed discussions took place between teachers of physics and physiology. The most tightly coupled problems between physics and physiology involve electricity and nerve cells. According to medical teachers, students have many problems in understanding this highly complex topic, thus we focused on this theme.

In physics, students become acquainted with the concepts of voltage, potential, current, resistance, electric insulation, and capacitance. These concepts are the biophysical basis for the conductance of ion channels, the capacity and the resistance of a membrane and the insulation by myelin. In physiology, the excitation of membranes, action potentials and electrotonic, continuous and saltatoric propagation of excitations are discussed [15-18].

All the physical concepts mentioned above are examined in the context of electricity experiments in a physics laboratory. The different designs of the corresponding experiments are explained within two selected examples.

\section{Resistance of an electric conductor}

In a standard experiment the length dependence of the resistance of an electric conductor is explored via measurements of the voltage drop along the conductor. This is the basis for Poggendorf's method of compensation or the Wheatstone bridge. In an addressee-specific experiment the resistances of conductors with different lengths and cross 


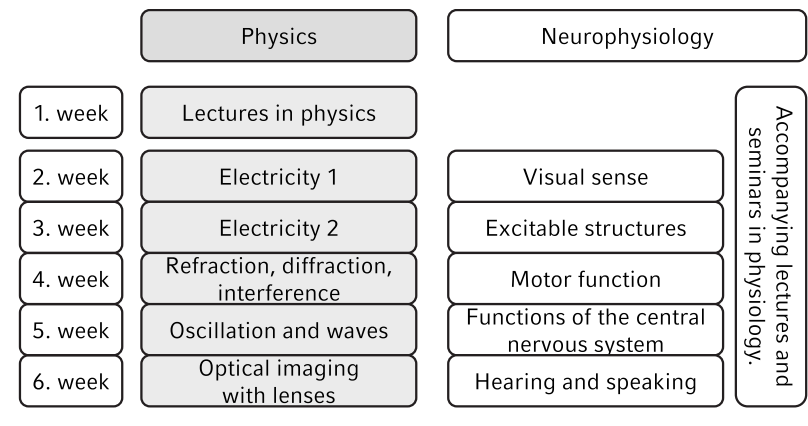

FIG. 3. Schedule for the first part of the third semester.

sections are measured directly and the results are discussed in the context of modeling a nerve cell. In this case the physiological utility describing the nerve cell as a long cylindrical conductor is explicitly discussed.

\section{Capacitor}

On the basis of a serial circuit of a resistor and a capacitor, the frequency dependence of the reactance can be quantified, and with the addition of an inductivity, the resonance of an $L C$ oscillator can be observed. In the addressee-specific experiment, the charging process of a parallel $R C$ circuit is measured, and the time constant $\tau$ is determined as a parameter of the cell membrane. The meaning of $\tau$ with respect to the propagation speed of excitation is discussed, focusing also on the effect of a varying capacitance.

In this way, two standard experiments were replaced by two newly designed addressee-specific experiments, which also meet the suggestions of the Association of American Medical Colleges [11]. The examples given above are embedded in the new laboratory. More details will be given in a forthcoming paper.

\section{STUDY DESIGN}

\section{A. Curriculum at the Ludwig-Maximilians-University of Munich}

At the LMU the courses in physics and in physiology are taught in parallel during the third and the fourth semester of a four semester sequence. Figure 3 shows the schedule for the first part of the third semester with its focus on neurophysiology. Except for the lectures all course activities take place in 40 classes of 20 students each, into which the students are divided randomly.

The lectures in physics take place in the first week. In the following five weeks the students perform and are tested on five physics experiments. Students receive an instructional textbook for the laboratory course [19], in which all essential background information, the procedure and the analysis of the experiments are described in detail. The students require no additional material beyond the instructional text containing about 12 pages per experiment.

Students must prepare at home and take a short oral test at the beginning of each experiment. Each laboratory lasts for three hours, in which students perform experiments in teams of two and analyze their measurements. Each class of students is assisted by two tutors.
A practical class in physiology [20] lasts $4.5 \mathrm{~h}$ and is accompanied by a prepractical discussion class $(1.5 \mathrm{~h})$ before and a debriefing $(1.5 \mathrm{~h})$ after each laboratory session. Lectures and seminars in physiology take place during each week. Except for the lectures in physics and in physiology attendance is compulsory. Because of the timing between physics and physiology students generally are exposed to certain concepts and laws of physics a few days before they need exactly these in their practical course in physiology.

\section{B. Research questions}

Until 2008/09, the laboratory course in physics contained only standard experiments, especially two experiments in electricity during the third semester. A few days later the students usually attended a prepractical discussion class for physiology on excitable structures (Fig. 3). In this class a medical teacher repeated the relevant biophysical basics. The students were left to their own devices to synthesize the physics and physiology concepts (Sec. II C). Afterward students should have understood enough to be able to gain further knowledge from the laboratory class in physiology. This led to the following research questions:

RQ1 Are students able to relate the concepts of physics, which they learned within the standard experiments, to concepts of physiology without outside intervention?

RQ2 Can a more profound understanding and a better transfer of knowledge be achieved by addressee-specific experiments?

Although the students learn the same physical concepts in standard and addressee-specific experiments, they no longer deal with "purely physical" applications and problems in the latter case. Thus a physics teacher might have reservations about introducing addressee-specific experiments.

RQ3 Are addressee-specific experiments performed at the expense of substance and standards of a standard laboratory course in physics?

\section{Methodology}

The research questions were addressed in a field study. The expectations and needs of the medical teachers for the physiological experiment "excitable structures" were mapped in newly developed assessment instruments. The standard experiments were examined with respect to the learning outcome and were compared to the modified laboratory, which introduced addressee-specific experiments into the physics course. The new experiments contained the same physical concepts as the standard experiments, albeit in a different context, and were similar to the remaining laboratory experiments with regard to difficulty and time required. A detailed article on an additional evaluation of the difficulty, required time, and medical relevance of the experiments is in progress.

The remaining experiments of the physics laboratory course and also the lectures, seminars, prepractical discussion classes, and physiology laboratories were not modified. Students of the winter semester 2008/09 (standard experiments) will subsequently be referred to as the control group (CG), and the students of the winter semester 2009/10 
Construct a concept map, using the following concepts. Membrane, Myelin, Resistor, Electric Insulator, Ion Channel, Capacitor, RC-element

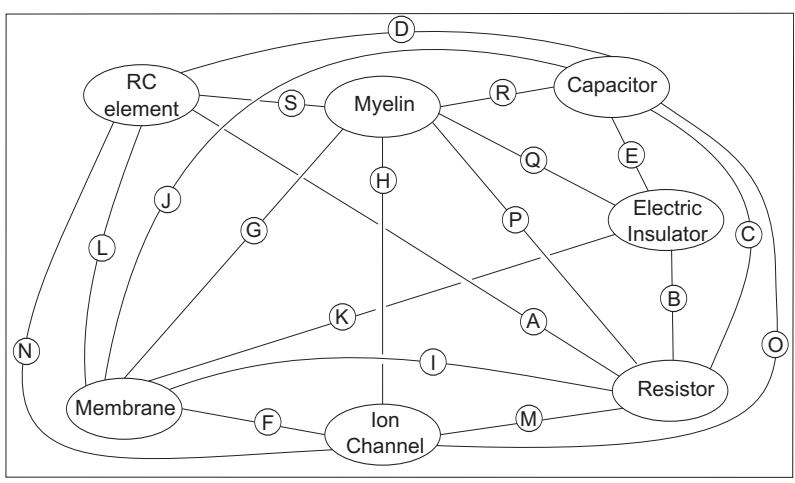

FIG. 4. An expert's map, containing 19 propositions.

(addressee-specific experiments) will be referred to as the treatment group (TG). 16 classes per year were chosen for this study, so that each sample consisted of about 300 students.

The assessment was administered at the beginning of the experiment "excitable structures" within the physiology laboratory. Organizational restrictions precluded a pretest being performed. The temporal distance between the assessment and the final exams of this semester was at least eleven days for all students. That way, the knowledge assessed was that, which the students had acquired during their regular courses but not while preparing independently for their final exams. For that reason a delayed posttest was not used for this study. The assessment consisted of the construction of a concept map [21] and some additional multiple choice (MC) questions.

\section{Assessment design}

In the first part of the assessment, students were asked to construct a concept map. Concept mapping has been established as a diagnostic tool to assess the declarative knowledge of a large number of students [22]. This method has a low degree of suggestive power [23]. As students were asked to construct the map from scratch, the test instrument provided an intuitive access to fragments of knowledge, held by the students, because they could give answers about single propositions, even if the entire subject was not understood in detail. Furthermore, misconceptions could be identified [24,25].

Students were asked to use the following concepts: membrane, myelin, resistor, electric insulator, ion channel, capacitor, and $R C$ element. The positions of membrane, myelin and resistor were fixed, while students had to arrange all other concepts and phrase the propositions. An expert's map is shown in Fig. 4, the corresponding propositions are given in Table I.

The second part of the assessment contained eleven MC questions. The content of the questions is based on the country-wide examination in preclinical sciences set by the Institute for Medical and Pharmaceutical Examination Questions (IMPP) [26]. All questions were newly designed and addressed the same topic, focusing on conceptual and quan-
TABLE I. Answers to the expert's map in Fig. 4.

\begin{tabular}{lc}
\hline \hline & Pure physics propositions \\
\hline A & A resistor is part of an $R C$ element \\
B & An electric insulator has an almost infinite \\
resistance
\end{tabular}

titative understanding. They were intended to check the validity of the concept maps.

The item difficulty level $P$, the point biserial coefficient $r_{\text {pbi }}$, and the discrimination index $D$ were calculated with the assessment results being considered as an internal criterion for the latter. Subsequently one of the eleven questions was excluded. The remaining MC questions are given in Table II. Additionally the Kuder-Richardson reliability index $r_{\text {test }}$, Cronbach's $\alpha$ and Ferguson's $\delta$ were evaluated. The values for the ten questions are given in Tables III and IV. All of them are in an acceptable range [27-29].

Whereas concept mapping as assessment instrument was unknown to all students assessed (except one), all medical students were very familiar with multiple choice questions.

\section{E. Assessment procedure}

The assessment development was followed by a trial phase, in which seven medical students performed both parts of the assessment, shortly after passing their courses in physics and physiology. In preparing for their exams in both subjects, they had acquired and synthesized the knowledge nec- 
TABLE II. MC questions used in the assessment. The correct answer is printed in italics, the fraction of correct answers is given each for control group and treatment group in brackets. For all questions the answer "I don't know" was given in addition.

In which way can a nerve cell's membrane not be modeled?

$$
R C \text { element }
$$

Parallel circuit of resistor and capacitor

Serial circuit of resistor and capacitor

The velocity of electrotonic propagation of excitation is a function of the following physical quantity

$$
\begin{gathered}
\text { Length constant } \lambda \\
\text { Time constant } \tau \\
\text { Permeability } \mu
\end{gathered}
$$

A membrane has properties of a capacitor. Which statement is not correct?

Intra- and extracelluar is equal to a capacitor's conductors

The double lipid layer is an electric insulator.

The hydrophilic heads on the membrane's outside correspond to a capacitor's conductors, the hydrophobic body in between is the electric insulator.

Because of myelin the resistance of a membrane ...

... increases.

... decreases.

... stays the same.

Because of myelin the capacity of a membrane ...

$$
\begin{gathered}
\text {... increases. } \\
\ldots \text { decreases. } \\
\ldots \text { stays the same. }
\end{gathered}
$$

Because of myelin the length resistance of an axon ...

$$
\begin{gathered}
\text {... increases. } \\
\ldots \text { decreases. } \\
\text {... stays the same. }
\end{gathered}
$$

Because of myelin the leakage current ...

$$
\begin{gathered}
\text {... increases. } \\
\ldots \text { decreases. } \\
\ldots \text { stays the same. }
\end{gathered}
$$

Because of myelin the time constant $\tau$..

$$
\begin{gathered}
\text {... increases. } \\
\ldots \text { decreases. } \\
\ldots \text { stays the same. }
\end{gathered}
$$

Because of myelin the length constant ...

... increases.

... decreases.

... stays the same.

How does an action potential propagate between the nodes of Ranvier?

Saltatoric

Electrotonic

$(0.16 / 0.47)$

Continuous 
TABLE III. Item analysis: Mean $M$ and standard deviation $S D$ for ten MC questions with item difficulty level $P$, point biserial coefficient $r_{\mathrm{pbi}}$ and (internal) discrimination index $D$.

\begin{tabular}{lcccc}
\hline \hline Item statistics & $M$ & $S D$ & Range & Desired values \\
\hline$P$ & 0.51 & 0.18 & {$[0.30,0.89]$} & {$[0.30,0.90]$} \\
$r_{\mathrm{pbi}}$ & 0.45 & 0.09 & {$[0.30,0.61]$} & $\geq 0.20$ \\
$D$ & 0.61 & 0.14 & {$[0.31,0.82]$} & $\geq 0.30$ \\
\hline \hline
\end{tabular}

essary to perform well on the assessment. For each student the assessment was accompanied by an interview to clarify the MC questions and on how to properly construct a concept map. This resulted in minor adaptations of the final version.

The assessment was given at the beginning of the physiology laboratory on nerve cells. The designer of the assessment (MP) gave a brief introduction, outlining how to create a concept map. The students were given $30 \mathrm{~min}$ to complete the assessment. To avoid copying both parts of the assessment were distributed and collected successively. The medical teachers ensured that students worked alone. Discussions with students indicate that none of them anticipated the assessment.

In the following all concept maps were rated by one of the authors (MP). A relational scoring method was chosen because holistic or structural approaches have a lower reliability [30,31]. The scoring method was simplified by assigning the same weight to each proposition, because the simple structure of most of the propositions hardly allows further discrimination.

In this way scores, $S$, were calculated for each student by counting the particular number of correctly phrased propositions of the concept map. $S_{\text {medicine }}$ represents pure medicine, $S_{\text {physics }}$ pure physics and $S_{\text {transfer }}$ interdisciplinary knowledge. The scores $S_{\text {map }}$ and $S_{\mathrm{MC}}$, respectively, correspond to the sum of all correctly phrased propositions in the concept map and of all correct answers to the MC questions.

\section{F. Assessment quality criteria}

\section{Objectiveness}

a. Comparability of $C G$ and TG. Because of the absence of a pretest, the quality of the students of both years must be about the same, otherwise the assessment results by control and treatment groups will be difficult to compare. Medical students at the University of Munich are admitted after a series of selection procedures (three rounds), based on their

TABLE IV. Assessment analysis: Measured and desired values for the Kuder-Richardson reliability index $r_{\text {test }}$, Cronbach's $\alpha$ and Ferguson's $\delta$.

\begin{tabular}{lcc}
\hline \hline & Assessment statistics & Desired values \\
\hline$r_{\text {test }}$ & 0.80 & $\geq 0.70$ \\
$\alpha$ & 0.71 & $\geq 0.60$ \\
$\delta$ & 0.98 & $\geq 0.90$ \\
\hline
\end{tabular}

TABLE V. Admission cutoff grades for students beginning a medical course in Munich in the last five years . Grades are given in the German style: 1 (highest) to 6 (lowest); passing grades $1-4$. In selection round I $20 \%$ of the available places are assigned solely by the students' grades. The next $60 \%$ of places are awarded in round II on the basis of grades plus additional criteria. In round III the final $20 \%$ of places are awarded on the basis of grades and the duration of the waiting period.

\begin{tabular}{lccc}
\hline \hline & I & II & III \\
\hline Winter 05-06 & 1.2 & 1.6 & 4.2 \\
Winter 06-07 & 1.1 & 2.2 & 1.5 \\
CG (winter 2007-08) & $\mathbf{1 . 0}$ & $\mathbf{1 . 5}$ & $\mathbf{2 . 6}$ \\
TG (winter 2008-09) & $\mathbf{1 . 1}$ & $\mathbf{1 . 5}$ & $\mathbf{2 . 6}$ \\
Winter 09-10 & 1.1 & 1.5 & 3.5 \\
\hline \hline
\end{tabular}

final average school grade [32]. Admission is restricted (numerus clausus), and the cutoff grades of the last five annual intakes are shown in Table V. The intake years from which the study groups were obtained are shown in bold. There is no evidence suggesting a performance difference between the two years. When the students reached the third semester, they were divided into 40 classes of 20 students each. This selection was random. In summary, comparability can be assumed, because of the randomly selected sample of two similar years.

b. Assessment procedure. Leading up to the assessment, all students were given the same instructional information and the same amount of time. In both years the elapsed time between the laboratory courses in physics, the prepractical discussion class, and the assessment were similar (Table VI). In both years the same physics and medicine concepts were taught within the pre-practical discussion class. All students (with one exception) were novices in concept mapping; they were unaware of this assessment and had never seen a concept map on this topic before.

\section{Reliability}

To ensure the reliability of the evaluation, 77 randomly selected concept maps were rated independently by the designer of the assessment (MP), a physiologist (MM) and a physicist $(\mathrm{KJ})$. Each has expert knowledge within their respective fields. Apart from some basic information about

TABLE VI. Average time interval $M$ in days between the assessment and the physics experiments "Electricity 1," "Electricity 2 " and the pre-practical discussion class for the classes of the control group $(N=16)$ and the treatment group $(N=16)$.

\begin{tabular}{lrrrrrr}
\hline \hline & \multicolumn{2}{c}{$\mathrm{CG}$} & & & \multicolumn{2}{c}{$\mathrm{TG}$} \\
\cline { 2 - 3 } \cline { 6 - 7 } & \multicolumn{1}{c}{$M$} & $S D$ & & $M$ & $S D$ \\
\hline Electricity 1 & 10.7 & 1.5 & & 12.0 & 1.6 \\
Electricity 2 & 2.9 & 1.6 & & 4.1 & 1.6 \\
Prepractical discussion class & 2.8 & 1.4 & & 3.4 & 1.8 \\
\hline \hline
\end{tabular}


TABLE VII. Means and standard deviations of Cohen's $\kappa$ for different correctors. $\kappa$ was calculated for all propositions $(N=19)$.

\begin{tabular}{lcc}
\hline \hline & $M$ & $S D$ \\
\hline$\kappa_{\mathrm{MP} / \mathrm{MM}}$ & 0.71 & 0.18 \\
$\kappa_{\mathrm{MP} / \mathrm{KJ}}$ & 0.71 & 0.18 \\
$\kappa_{\mathrm{MM} / \mathrm{KJ}}$ & 0.62 & 0.24 \\
\hline \hline
\end{tabular}

concept mapping, no further instructions were given nor were there any concluding discussions. By the standards of Landis and Koch [33] there was substantial agreement between all three evaluations (Table VII).

\section{Validity}

Concept mapping is a challenging assessment instrument, because students have to arrange the concepts and phrase the propositions themselves. Since students might have problems with verbalization or "lose their way" within their concept map, concept mapping probably underestimates the students' knowledge. At the same time the score of the MC questions might be too high because of the guess probability.

To ensure the validity of the assessment, the scores within the concept map, $S_{\text {map }}$, and the MC questions, $S_{\mathrm{MC}}$, were compared. The correlation of Pearson $r$ with level of significance $p$ was large $(r=0.71, p<0.001)$ [34]. A more detailed look at the individual groups showed a difference. The correlation was small for the control group $\left(r_{\mathrm{CG}}=0.29, p\right.$ $<0.001)$ and large for the treatment group $\left(r_{\mathrm{TG}}=0.60, p\right.$ $<0.001)$.

For the control group the resulting mean, $\bar{S}_{\mathrm{MC}}^{\mathrm{CG}}=3.45$, was close to the value of 3.33 stemming from the guess probability. Therefore the lower value for the control group's correlation could be explained. Altogether, these values were within the typical range [35]. One has to keep in mind, that concept mapping is sensitive to other abilities in comparison with conventional performance tests [36].

\section{RESULTS AND DISCUSSION}

\section{A. Assessment results}

After rating all concept maps, the relative frequency was calculated for every proposition. The resulting values are presented in Table VIII and illustrated in Fig. 5. In the following, the different scores mentioned above were calculated for every map. The means $M$ and standard deviations $S D$ are shown in Table IX. After testing variances for equality (Levene F-test), a T-test or, alternatively, a Welch-test for independent samples was performed and Cohen's $d$ [37] was calculated.

\section{B. Knowledge transfer within standard experiments}

Figure 6 shows a concept map, which is typical for the students of the control group. The score $S_{\text {map }}$ of this map matches the mean $(M=5.08)$ and most frequently phrased propositions were plotted. This demonstrates a lack of network structure and a bad linkage between some concepts. In
TABLE VIII. Relative frequency of correctly phrased propositions for control group $(N=287)$ and treatment group $(N=287)$.

\begin{tabular}{lccc}
\hline \hline & & $\mathrm{CG}$ & $\mathrm{TG}$ \\
\hline $\mathrm{A}$ & Resistor- $R C$ element & 0.171 & 0.832 \\
$\mathrm{~B}$ & Resistor-Electric insulator & 0.181 & 0.237 \\
$\mathrm{C}$ & Resistor-Capacitor & 0.413 & 0.087 \\
$\mathrm{D}$ & Capacitor- $R C$ element & 0.181 & 0.819 \\
$\mathrm{E}$ & Capacitor-Electric insulator & 0.114 & 0.421 \\
$\mathrm{~F}$ & Membrane-Ion channels & 0.930 & 0.920 \\
$\mathrm{G}$ & Membrane-Myelin & 0.463 & 0.700 \\
$\mathrm{H}$ & Myelin-Ion channels & 0.098 & 0.254 \\
$\mathrm{I}$ & Membrane-Resistor & 0.376 & 0.516 \\
$\mathrm{~J}$ & Membrane-Capacitor & 0.376 & 0.774 \\
$\mathrm{~K}$ & Membrane-Electric insulator & 0.174 & 0.341 \\
$\mathrm{~L}$ & Membrane- $R C$ element & 0.087 & 0.557 \\
$\mathrm{M}$ & Ion channel-Resistor & 0.251 & 0.798 \\
$\mathrm{~N}$ & Ion channel- $R C$ element & 0.010 & 0.199 \\
$\mathrm{O}$ & Ion channel-Capacitor & 0.010 & 0.028 \\
$\mathrm{P}$ & Myelin-Resistor & 0.192 & 0.645 \\
$\mathrm{Q}$ & Myelin-Electric insulator & 0.885 & 0.944 \\
$\mathrm{R}$ & Myelin-Capacitor & 0.160 & 0.394 \\
$\mathrm{~S}$ & Myelin- $R C$ element & 0.010 & 0.111 \\
\hline \hline
\end{tabular}

particular the $R C$ element was not connected to other concepts by almost $80 \%$ of the students of the control group.

The score $S_{\text {transfer }}$ represents the interdisciplinary knowledge. Its maximum possible value was $S_{\text {transfer }}=11$. The resulting mean of $2.54(S D=1.29)$ demonstrated that students were not able to connect the concepts of physics and physiology within the standard experiments.

Therefore RQ1 could be answered negatively:

Students are not able to relate physical and medical concepts, which they learned in the standard experiments.

\section{Knowledge transfer within addressee-specific experiments}

A representative concept map for students in the treatment group is given in Fig. 7. This map is characterized by a

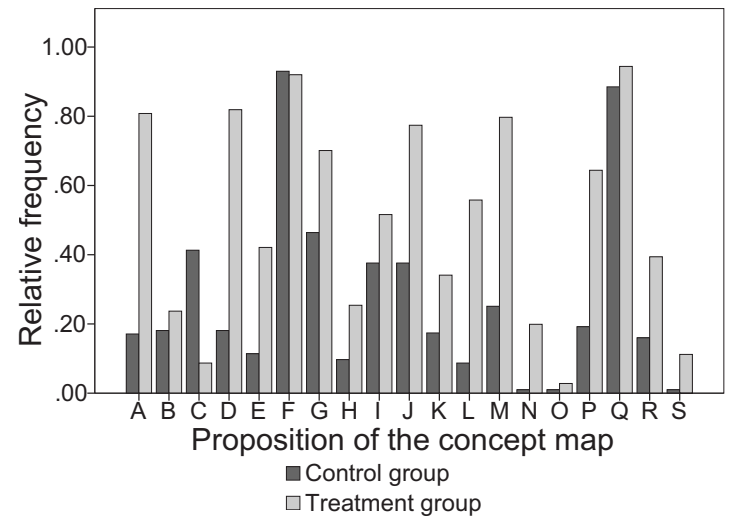

FIG. 5. Relative frequency of correctly phrased propositions for CG and TG. Propositions' labels correspond to the expert's map (Table I and VIII). 
TABLE IX. Means $M$ and standard deviations $S D$ of different scores for control group $(N=287)$ and treatment group $(N=287)$ with level of significance $(* * * p<.001)$ and Cohen's $d$.

\begin{tabular}{|c|c|c|c|c|c|c|}
\hline & \multicolumn{2}{|c|}{$\mathrm{CG}$} & \multicolumn{2}{|c|}{ TG } & \multirow[b]{2}{*}{$p$} & \multirow[b]{2}{*}{$d$} \\
\hline & $M$ & $S D$ & $M$ & $S D$ & & \\
\hline$S_{\text {map }}$ & 5.08 & 2.01 & 9.58 & 2.90 & $* * *$ & 1.80 \\
\hline$S_{\mathrm{MC}}$ & 3.45 & 1.69 & 6.72 & 1.94 & $* * *$ & 1.80 \\
\hline$S_{\text {medicine }}$ & 1.48 & 0.65 & 1.86 & 0.75 & $* * *$ & 0.55 \\
\hline$S_{\text {physics }}$ & 1.06 & 1.04 & 2.40 & 1.10 & $* * *$ & 1.25 \\
\hline$S_{\text {transfer }}$ & 2.54 & 1.29 & 5.32 & 2.00 & $* * *$ & 1.65 \\
\hline
\end{tabular}

distinctively higher network structure and much better linkage of all concepts.

All the scores (Table IX) increased highly significantly, which resulted in very strong effect sizes [37] in most cases. The results for the interdisciplinary knowledge, represented by the mean of $S_{\text {transfer, improved from } 2.54 \text { for the control }}$ group to 5.32 with a standard deviation of $S D=2.00$ for the treatment group. This is illustrated in Fig. 8.

Taken together RQ2 can be answered affirmatively:

Addressee-specific physics experiments are an effective way to help students to understand physics and physiology.

\section{Physics knowledge}

With respect to pure physics propositions, the evaluation of the concept maps shows an increase in the mean of the score $S_{\text {physics }}$ from 1.06 for the control group $(S D=1.04)$ to 2.40 for the treatment group $(S D=1.10)$. Although this is a highly significant improvement with a strong effect size, a more detailed examination of the individual propositions (Table VIII) is necessary to answer RQ3.

Students of the control group measured the frequency dependence of the capacitive reactance. The corresponding proposition "resistor-capacitor" was phrased by $41.3 \%$, while the percentages of the remaining propositions are half as high and all below 20\%. Within the addressee-specific experiments, the experimental setup was replaced by a parallel

Construct a concept map, using the following concepts.

Membrane, Myelin, Resistor, Electric Insulator, Ion Channel, Capacitor, RC-element

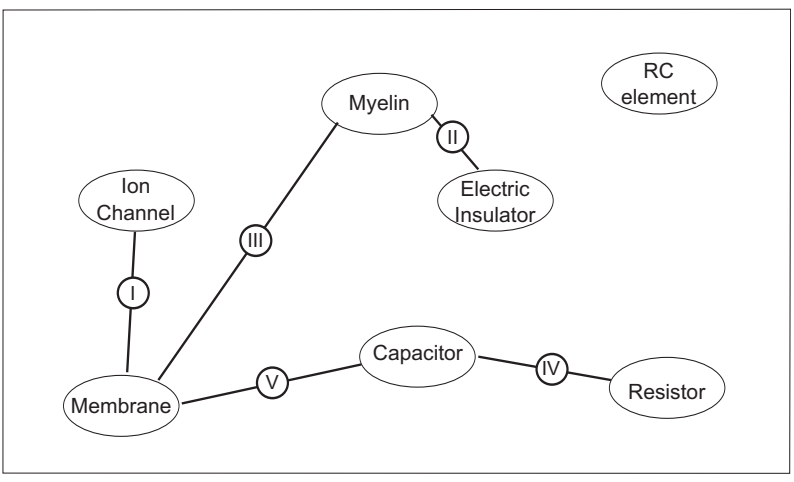

FIG. 6. A concept map, representative for the level of knowledge of the control group. The propositions are labeled downward according to their frequency of occurrence (I-V). circuit of a resistor and a capacitor, whereas the capacitive reactance measurement was no longer part of the modified physics laboratory course. As expected, this changed the rates of the different propositions. While "resistor-capacitor" decreased by a factor of 4.7 , the propositions "resistor- $R C$ element" and "capacitor- $R C$ element" increased by factors of 4.9 and 4.5 , respectively. This relative change was not surprising. But the differences in the absolute percentages were even greater: More than $80 \%$ of the students of the treatment group phrased the propositions about the assembling of an $R C$ element, which was about twice as frequent as "resistorcapacitor" in the control group. Furthermore, the values for the remaining pure physics propositions improved, even though they were not specifically emphasized in the experiments.

The additional combination between concepts of physics and medicine and-according to physics tutors-an increasing motivation seemed to support enhanced learning of pure physical concepts and laws.

Based on the data of this study RQ3 could be answered negatively:

Addressee-specific experiments are not necessarily performed at the expense of substance and standards of a physics laboratory course.

\section{E. Experience from the laboratory's daily routine}

From the students' point of view, the physics laboratory course with standard experiments has no medical relevance.

Construct a concept map, using the following concepts.

Membrane, Myelin, Resistor, Electric Insulator, Ion Channel, Capacitor, RC-element

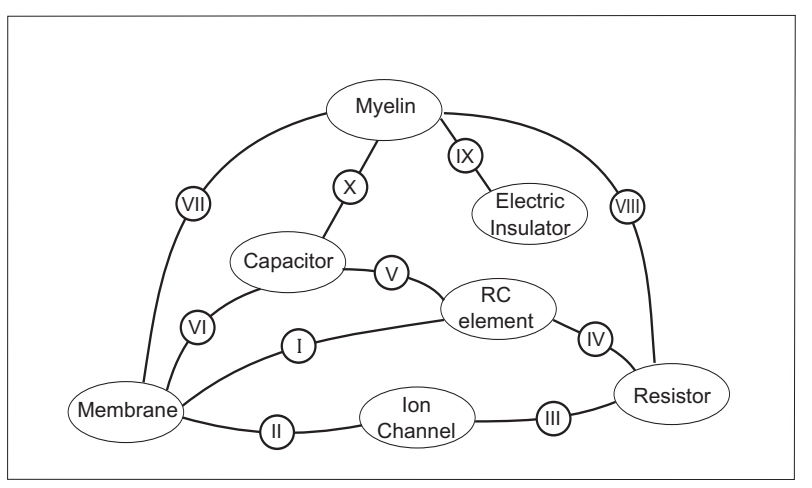

FIG. 7. A concept map, representative for the level of knowledge of the treatment group. The propositions are labeled downward according to their frequency of occurrence (I-X). 


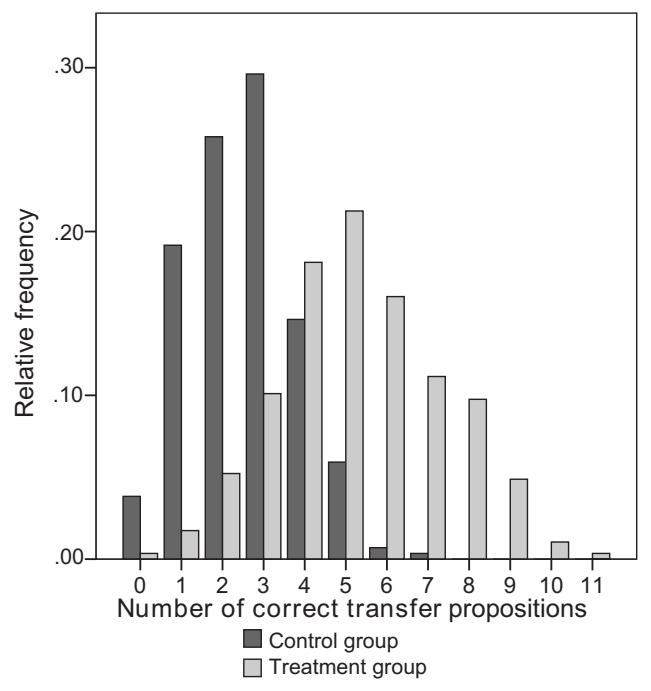

FIG. 8. Distribution of $S_{\text {transfer }}$ for control group and treatment group.

These complaints were reported periodically by members of the physics faculty, who supervised the experiments. Tutors were thus occupied by student motivation and laboratory ambience improvement instead of assisting during experimentation and explaining physical contexts.

This situation changed totally after introducing the new experiments on electricity. Although the workload in the laboratory was not less, there was a higher morale on the students' part. Tutors reported the students' opinion that the physics laboratory was not as bad as their fellows students claimed and that students profited from their physics course for the first time. Additionally, lively discussions took place on physical aspects of the students' physiological textbooks.

\section{CONCLUSION AND IMPLICATIONS}

In this study the learning effectiveness within the physics laboratory course was examined from a physiologist's point of view. Standard and newly developed addressee-specific experiments were compared.

In the first step of this study, we saw that, as a rule, standard experiments were not sufficient for teaching physics in a physiologically meaningful manner. Although students of both years learned the same physics concepts in different courses, students of the control group were not able to relate concepts of physics and medicine.

New addressee-specific experiments on electricity were designed. They contained the same physics concepts but were closely connected to medicine and addressed these physics concepts within a physical and medical content.

This study demonstrated that introducing addresseespecific experiments was an effective means of assisting students in understanding physiology, giving them a physical basis for learning about neural functions. Not only did students, being exposed to the addressee-specific experiments, achieve higher scores in transfer questions, they also got higher scores in pure physics questions. According to the feedback of the tutors, students were also more aware of the medical relevance of the physics laboratory course.

Taken together, addressee-specific experiments in physics appeared to constitute a considerable gain in medical education. Furthermore, comparisons to the control group showed that students could not successfully relate concepts of physics and medicine without explicit intervention. The increased understanding, better assessment results, and higher motivation demonstrated that these physics experiments were an adequate instrument to teach physics in a physiologically meaningful manner.

\section{ACKNOWLEDGMENTS}

The authors would like to thank John Davis from LMU Munich and Mark Reeves from George Washington University, who provided extensive feedback which significantly helped to improve this paper. One of the authors (MP) acknowledges the support of the Hanns-Seidel-Stiftung.
[1] A. B. Arons, Guiding Insight and Inquiry in the Introductory Physics Laboratory, Phys. Teach. 31, 278 (1993).

[2] American Association of Physics Teachers, Goals of the Introductory Physics Laboratory, Am. J. Phys. 66, 483 (1998).

[3] M. Welzel et al., Teachers' Objectives for Labwork. Research Tool and Cross Country Results, in Working Paper 6 from the European project Labwork in Science Education (Targeted Socio-Economic Research Program, Project PL 95-2005), 1998.

[4] H. Theyßen, Ein Physikpraktikum für Studierende der Medizin (Logos Verlag, Berlin, 2000).

[5] A. Hofstein and V. N. Lunetta, The Role of the Laboratory in Science Teaching: Neglected Aspects of Research, Rev. Educ. Res. 52, 201 (1982).

[6] V. N. Lunetta, in International Handbook of Science Teaching, edited by B. Fraser and K. Tobin (Kluwer, Dordrecht, 1998), pp. 249-264.

[7] A. Hofstein and R. Mamlok-Naaman, The laboratory in science education: the state of the art, Chem. Educ. Res. Pract. 8, 105 (2007).

[8] W. S. Toothacker, A critical look at introductory instruction, Am. J. Phys. 51, 516 (1983).

[9] V. N. Lunetta, A. Hofstein, and M. Clough, in Handbook of Research on Science Education, edited by N. Lederman and S. Abel (Lawrence Erlbaum, Mahwah, New York, 2007), pp. 393-441.

[10] T. S. Volkwyn, S. Allie, and A. Buffler, Impact of a conventional introductory laboratory course on the understanding of measurement, Phys. Rev. ST Phys. Educ. Res. 4, 010108 (2008).

[11] AAMC-HHMI, Scientific Foundations for Future Physicians, 
http://www.hhmi.org/grants/sffp.html most recently accessed June 23rd 2010.

[12] P. Tamir and V. N. Lunetta, Inquiry Related Tasks in High School Science Laboratory Handbooks, Sci. Educ. 65, 477 (1981).

[13] G. Kortemeyer, The Challenge of Teaching Introductory Physics to Premedical Students, Phys. Teach. 45, 552 (2007).

[14] P. S. Shaffer and L. C. McDermott, Research as a guide for curriculum development: An example from introductory electricity. Part II: Design of instructional strategies, Am. J. Phys. 60, 1003 (1992).

[15] E. R. Kandel, J. H. Schwartz, and T. M. Jessell, Principles of Neural Science (Mcgraw-Hill Professional, 2000), pp. 105174.

[16] A. L. Hodgkin and A. F. Huxley, A quantitative description of membrane current and its application to conduction and excitation in nerve, J. Physiol. 117, 500 (1952).

[17] I. Herman, Physics of the Human Body: A Physical View of Physiology (Springer Verlag, Berlin, 2007), pp. 720-742.

[18] C. Koch, Biophysics of Computation: Information Processing in Single Neurons (Oxford University Press, New York, 1999).

[19] Fakultät für Physik der LMU München-Physikalische Praktika, Praktikum der Physik für Studierende der Humanmedizin. Anleitungen $z u \quad$ den Experimentellen Übungen, http://www.physik.uni-muenchen.de/studium/praktikum/ medizin/versuche/versuche.htm for login contact georgi.rangelov@physik.uni-muenchen.de.

[20] Physiologisches Institut der LMU München, Anleitung zum physiologischen Praktikum: Teil 1-Neurophysiologie. Teil 2-Vegetative Physiologie (München, 2009).

[21] J. D. Novak, Concept mapping: a useful tool for science education, J. Res. Sci. Teach. 27, 937 (1990).

[22] D. C. Rice, J. M. Ryan, and S. M. Samson, Using Concept Maps to Assess Student Learning in the Science Classroom: Must Different Methods Compete? J. Res. Sci. Teach. 35, 1103 (1998).

[23] J. Peuckert, Schulische Wissensdiagnose mittels Concept Mapping, edited by DPG, Didaktik der Physik-Vorträge, Tagung
1999, pp. 215-220.

[24] M. A. Ruiz-Primo, S. E. Schulz, M. Li, and R. J. Shavelson, Comparison of the Reliability and Validity of Scores from Two Concept-Mapping-Techniques, J. Res. Sci. Teach. 38, 260 (2001).

[25] Y. Yin, J. Vanides, M. A. Ruiz-Primo, C. C. Ayala, and R. J. Shavelson, Comparison of Two Concept Mapping Techniques: Implications for Scoring, Interpretation and Use, J. Res. Sci. Teach. 42, 166 (2005).

[26] Institut für medizinische und pharmazeutische Prüfungsfragen, http://www.impp.de/ most recently accessed March 24th 2010.

[27] R. Donan, Basic Measurement and Evaluation in Science Instruction (National Science Teachers Association, Washington DC, 1980), p. 97.

[28] L. Cronbach, Coefficient alpha and the internal structure of tests, Psychometrika 16, 297 (1951).

[29] L. Ding and R. Beichner, Approaches to data analysis of multiple-choice questions, Phys. Rev. ST Phys. Educ. Res. 5, 020103 (2009).

[30] J. R. McClure, B. Sonak, and H. K. Suen, Concept Map Assessment of Classroom Learning: Reliability, Validity and Logistical Practically, J. Res. Sci. Teach. 36, 475 (1999).

[31] J. D. Novak and D. B. Gowin, Learning How to Learn (Cambridge University Press, New York, 1984).

[32] Zentralstelle für die Vergabe von Studienplätzen, Auswahlgrenzen, http://www2.zvs.de/ most recently accessed March 23rd 2010.

[33] J. Landis and G. Koch, The measurement of observer agreement for categorical data, Biometrics 33, 159 (1977).

[34] J. Cohen, Statistical power analysis for the behavioral sciences, 2nd ed. (Routledge Academic, 1988), p. 83.

[35] M. A. Ruiz-Primo and R. J. Shavelson, Problems and Issues in the Use of Concept Maps in Science Assessments, J. Res. Sci. Teach. 33, 569 (1996).

[36] J. D. Novak, D. Gowin, and G. Johansen, The use of concept mapping and knowledge vee mapping with junior high school science students, Sci. Educ. 67, 625 (1983).

[37] Ref. [34] pp. 24 ff. 